\title{
Improvement methods of mining enterprises wastewater compounds from nitrogen purification
}

\author{
Tatyana Tyuleneva ${ }^{1,2, *}$, and Gennady Studenok $^{3}$ \\ ${ }^{1}$ T. F. Gorbachev Kuzbass State Technical University, 650000 Kemerovo, 28 Vesennyaya st., Russian \\ Federation \\ ${ }^{2}$ T.F. Gorbachev Kuzbass State Technical University, Branch in Mezhdurechensk \\ ${ }^{3}$ Ural State Mining University, 620144, Ekaterinburg, 30 Kuybysheva st., Russian Federation
}

\begin{abstract}
A typical negative impact on water resources for mining companies engaged in blasting operations is the discharge of quarry and mine water contaminated with nitrogen compounds. The solution of the problem under consideration is assumed with an integrated approach based on the use of partially flooded abandoned mine workings already available at the enterprise as bioengineered structures. The article substantiates and confirms the possibility of using flooded abandoned open-pit mine workings for the treatment of wastewater from mines and quarries contaminated with nitrogen compounds from the most environmentally hazardous components by natural microbiological nitrification. The advantages and disadvantages of the applied cleaning methods are investigated. The possibility of applying the method of biological purification based on the use of flooded waste workings with the existing natural ecosystem is justified from the point of view of economic efficiency. The advantages of this method are described and the effectiveness of its application is confirmed.
\end{abstract}

\section{Introduction}

One of the main priorities for economic entities, including mining enterprises, is to preserve the environment and reduce its pollution. The mining industry, in addition to the negative impact on the atmosphere, the soil, causes great damage to water resources. Enterprises engaged in the extraction of minerals through blasting operations have a negative impact on mine and quarry waters. Typical pollutants whose concentrations in water sources exceed the maximum permissible values are compounds such as ammonium and nitrite nitrogen compounds. Their presence in wastewater is a direct result of the use of explosives containing ammonium nitrate in the extraction of minerals.

${ }^{*}$ Corresponding author: kta.bua@kuzstu.ru 
Modern anthropogenic impact on the environment has changed the nitrogen cycle, and has strengthened the processes that enrich all its components with nitrogen compounds (atmospheric air, natural reservoirs, soil). Due to the high mobility of nitrogen compounds, its anthropogenic impact on the environment, mainly on aquatic ecosystems, is associated with an increase in its content in water reservoirs [1].

The need to comply with the strict requirements of environmental legislation regarding the content of nitrogen compounds in technological and natural reservoirs creates technical and environmental problems for mining enterprises, and failure to comply with these requirements leads to multi-million payments for the discharge of pollutants $[2 ; 3]$. All this leads mining companies to the need to find economically feasible and environmentally beneficial methods for treating nitrogen-containing wastewater.

\section{Characteristic of the work}

An analysis of the applicability of existing methods for the treatment of quarry water with nitrogenous compounds shows the following.

1. Physico-chemical purification methods (adsorption, ion exchange, reverse osmosis) can be used to purify water and reduce the concentration of nitrogenous compounds (ammonium, nitrites and nitrates), but their use carries the risks of forming concentrated solutions containing other nitrogenous compounds formed as a result of a chemical reaction after application. This requires additional costs for the subsequent neutralization of these substances. In addition, these methods are usually focused on the purification of much smaller volumes of wastewater than quarry ones [4;5].

2. The use of chemical methods for the purification of quarry waters is impractical due to the increase in the content of nitrates in quarry waters and the significant operating costs associated with the purchase of expensive and energy-intensive equipment. Other disadvantages are the use of hypochlorite, which leads to an increase in the concentration of chlorides in the waters after their purification from nitrogenous compounds is completed, as well as additional costs for the purchase of the necessary reagents [6-8].

3. The limited use of biological purification methods based on nitrification and denitrification technologies is caused by the formation of significant volumes of chemically active sludge, the presence of which in the nitrification phase causes the need for its processing and further disposal, which in turn causes the need for the arrangement of waste disposal sites, as well as causes additional energy costs for aeration of mixtures consisting of wastewater and active sludge [9-11].

4. There are limitations in the use of bioengineering in technological structures due to the possibility of their operation only in the warm months of the year and the lack of sufficient space for their placement, and also the need for time required to complete the cycle of biological wastewater purification [12].

5. Such a method of biological purification as anaerobic, based on the ANAMMOX technology, is more acceptable due to the relatively lower amount of energy and the volume of waste generated in the form of sludge from chemically active substances, compared to other industrial methods of biological treatment, but requires increased capital costs for the construction of bio-treatment facilities [13].

The analysis of scientific research in the direction of minimizing the concentration of nitrogen compounds in wastewater allows to draw the following conclusions. In practice, mining companies use the biological purification method as the most effective in terms of its cost-effectiveness, which is due to the significant volume of wastewater discharged and the reagents used for their purification, and this makes the use of chemical and physicochemical methods unacceptable. The efficiency of biological purification methods is 23-99 
\%. [15] However, even the most environmentally friendly method of extraction requires the introduction of additional areas for the construction of biological purification facilities, and also the implementation of additional costs for their construction and operation. Engineering and design and organizational measures are related to the adaptation of technological processes of the mining enterprise in the field of drilling and blasting operations. At the same time, if organizational activities (for example, minimizing the loss of explosives during transportation and loading of wells and timely elimination of losses) are primarily related to production discipline. It can be implemented by retrofitting wells with explosives, then the implementation of measures aimed at preventing contamination of quarry water with nitrogen compounds concerns only reducing the content of nitrogen compounds in quarry water as a result of partial dissolution of explosives (among which nitrites are the most toxic) present in the quarry water due to the partial dissolution of explosives, and can not affect them.

Thus, the solution of the problem of wastewater purification from nitrogen-containing compounds in economically and environmentally appropriate ways is possible using an integrated approach. It must take into account the specifics of the implementation of mineral extraction, accompanied by significant volumes of wastewater. The essence of this approach is the application of a biological purification method that does not involve the withdrawal of new areas for bioengineering facilities, the formation of additional costs for construction and operation, but also provides the required quality of purification.

Based on the above, it can be assumed that a promising and economically viable method for mining companies can be the use of available partially flooded workings as the basis for bioengineering installations.

Considering the possibilities of using flooded mine workings as bioengineered structures for wastewater purification, it is important to pay attention to the components of the ecosystem formed after their decommissioning, and the duration of this process in these structures. It will take several years for the effective implementation of the microbiological transformation (nitrification) of nitrogen nitrite into nitrogen nitrate.

To implement the technology of quarry water purification from nitrogenous compounds in the conditions of wastewater disposal, the following conditions must be met [16]:

- the $\mathrm{pH}$ value in wastewater at a level that does not interfere with the process of microbiological transformation (nitrification), in the value from slightly acidic to slightly alkaline;

- the content of chemical compounds that do not interfere with the process of microbiological transformation (nitrification);

- the level of filling of the technological reservoir with quarry waters, which limits the negative impact on the hydrogeological and hydrochemical situation of the coastal area;

- geomechanical features of the mine working do not cause the activation of landslide phenomena when filling with wastewater.

In order to identify the possibility and subsequent practical implementation of the technology of quarry waters natural purification from nitrogenous compounds in the conditions of JSC "Uralasbest" from May to October, research and monitoring observations of the process of purification of these waters using spent quarry workings were carried out for 3 years [15]. Analysis concerned the chemical composition of the Quarry 1-2 water of in terms of nitrogen compounds (ammonium, nitrite and nitrate nitrogen) in relation to the chemical composition of the waste water of the «Tsentralnaya - Novaya» Mine. It showed that the concentration of nitrogen compounds in its waters is determined by a combination of parallel biological nitrification processes - the formation of nitrate nitrogen from ammonium and nitrite nitrogen, and the dilution of incoming wastewater with atmospheric precipitation and quarry water. 
The efficiency of water purification from the Quarry depends on the speed of the conversion processes of microbiological (nitrification) of ammonium and nitrites. The conditions of this technological reservoir allow to fulfill these tasks, since it was decommissioned 12 years ago with flooding. This made it possible to form a natural ecosystem in it with flora, ichthyoid and zoofauna corresponding to the water basins formed in similar conditions. The results of the conducted studies of application methods for treating nitrogen-containing wastewater from the «Tsentralnaya -Novaya» Mine entering the flooded Quarry 1-2 showed the feasibility of using it as a technological object for biological purification. According to the results of the research, it was found that the leading process that purifies wastewater from the most toxic nitrogen compounds (ammonium and nitrogen nitrite) is the process of natural microbiological transformation. The concentration in the reservoirs of Quarry 1-2 for nitrate nitrogen due to an increase in its content during the nitrification of ammonium and nitrogen nitrite is determined by dilution and partial assimilation by aquatic vegetation.

The results of monitoring the chemical composition of water in Quarry 1-2 in comparison with the composition of incoming quarry water from the «TsentralnayaNovaya» Mine, for ammonium, nitrite and nitrate nitrogen are shown in Fig. 1.

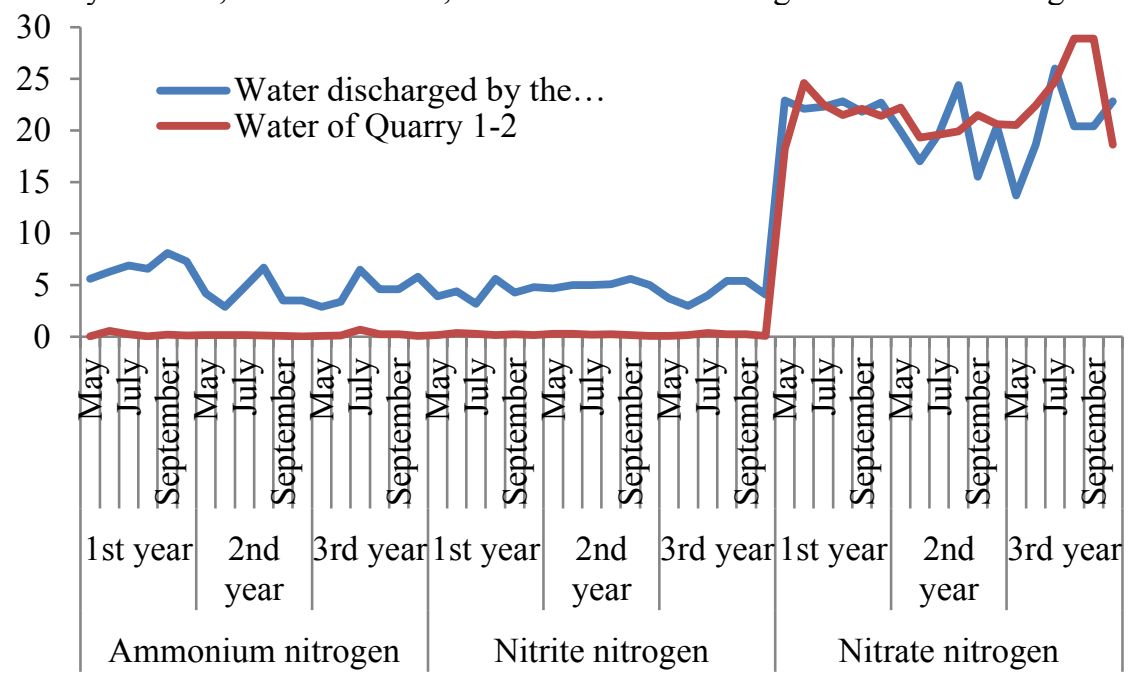

Fig. 1. Comparative analysis of the concentration of nitrogen compounds in wastewater and quarry waters, $\mathrm{mg} / \mathrm{dm}^{3}$

According to the data obtained, it can be concluded that the concentrations of the most toxic nitrogen compounds (ammonium and nitrites) in the quarry waters were ten times lower than in the mine wastewater. Deviations of their concentrations for months of 3 years from the average value in quarry waters are not as significant as in wastewater for similar periods, that is the "smoothing" effect of dilution with quarry waters positively characterizes the effectiveness of purification. For nitrate nitrogen there is an ambiguous dynamics and correlation of trends of change, which explains the influence of the biological environment of water resevoirs on the nitrification process. The biochemical destruction of ammonium contained in water leads first to the formation of nitrite ion, and then to the accumulation of nitrate ion, which are then used by phytoplankton and bacteria in the synthesis of nitrogen-containing cellular components. The concentration of nitrate nitrogen as it accumulates stabilizes which indicates a slowdown and the practical end of the biochemical processes of transformation of nitrogen compounds. 
Next, we will analyze the dynamics of the wastewater treatment efficiency indicator, that is, the ratio of the concentrations of nitrogen compounds of 3 types in the quarry and wastewater of the studied reservoir for similar periods (Fig. 2).

There is an increase in the concentration of nitrate nitrogen in the quarry waters in comparison with the incoming wastewater of the «Tsentralnaya - Novaya» Mine. This is caused by its accumulation as a result of the microbiological transformation (nitrification) of ammonium and nitrite nitrogen. At the same time the accumulation of nitrate nitrogen in quarry water is lower than during nitrification, which is caused by its partial absorption by aquatic plants. For 3 years of operation of Ouarry 1-2 as a technological facility for biological purification, stable results were obtained and they indicate the effectiveness of this method for the most toxic nitrogen compounds, while maintaining the nitrate nitrogen content at the level of indicators in the incoming wastewater.

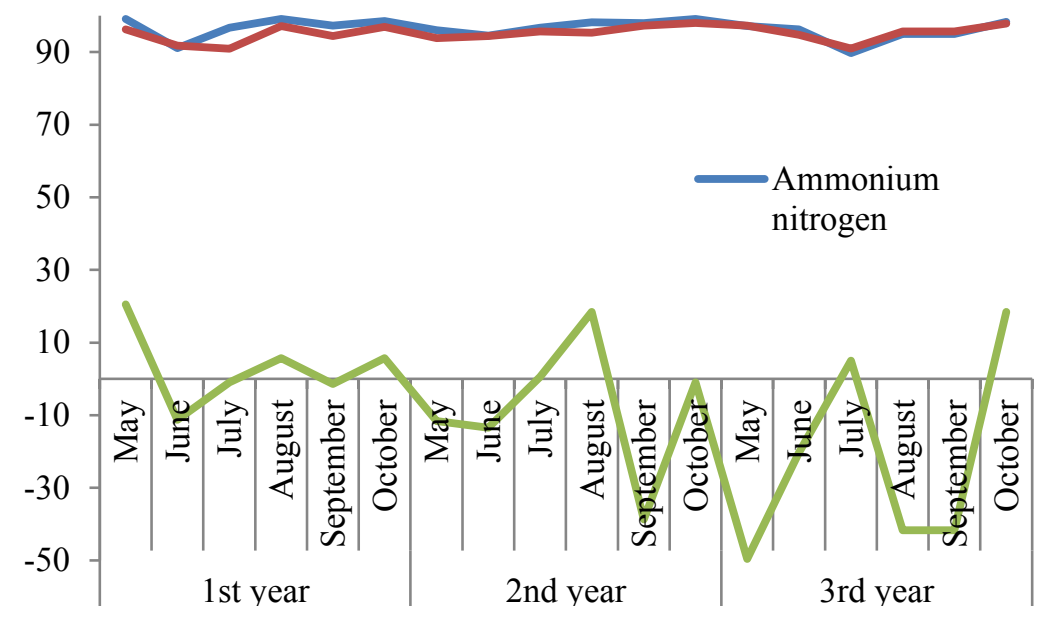

Fig. 2. The purification efficiency of nitrogen-containing wastewater Mine "Tsentralnaya-Novaya», $\%$

\section{Conclusion}

Mining with the simultaneous need to comply with the legal requirements for the protection of water bodies during the discharge of wastewater determines the rationale for choosing technologically and economically feasible technologies for their purification from nitrogenous compounds. As applied to the mining industry, the basis for the creation of engineering structures with the use of a biological method of purification can be used as spent mine workings that are naturally flooded by ground water and atmospheric precipitation.

In the course of the study, the possibility of using spent flooded mine workings to purify nitrogen-containing wastewater from mining enterprises from the most toxic compounds (ammonium and nitrite nitrogen) was proved, which showed an efficiency of more than 90 $\%$. The results of monitoring changes in the composition of quarry waters by the concentration of nitrogen compounds in the waters of the spent quarry confirm the possibility of using natural microbiological nitrification processes for purification. 


\section{References}

1. A.P. Pakusina, M.F. Tsarkova, T.P. Platonova, T.P. Kolesnikova, (IOP Conference Series: Earth and Environmental Science : conference proceedings, 2020)

2. L. Sagdeeva, L. Starikova, I. Trapeznikova, Life quality investments and environmental damage decreasing in coal mining regions (E3S Web of Conferences, 2019)

3. T. Tyuleneva, Environmental consequences of coal mine elimination (Proceedings of the 9th China-Russia Symposium "Coal in the 21st Century: Mining, Intelligent Equipment and Environment Protection", 2018)

4. N.D. Sorokin, D.E. Aleksandrov, I.D. Grodnitskaya, S.Y. Evgrafova, Eurasian Soil Science, 50, 476 (2017)

5. E. Berlinteyger, T. Tyuleneva, Ch. Malik, Use of irradiated flocculants for wastewater treatment (E3S Web of Conferences, 2019)

6. S. F. Bureiko, S. Y. Kucherov, IR spectra of cyclic hydrogen-bonded complexes of bifunctional nitrogen compounds in solution, (Optics and Spectroscopy, 2010)

7. W. Xiong, Z. Wang, S. He, F. Hao, Y. Lv Y. Yang, W. Zhang, P. Liu, H. Luo. Nitrogendoped carbon nanotubes as a highly active metal-free catalyst for nitrobenzene hydrogenation, 260, 118105 (2020)

8. Y.H. Robin Chang, T. L. Yoon, Effects of nitrogen addition and growth condition on the enhanced mechanical properties of transition metal carbides TMC (TM=ZR, HF) 46, 1124 (2020)

9. O.V. Skripko, S.A. Kostrykina. Biotechnological aspects of obtaining coagulation structures for functional foods, 32006 (IOP Conference Series: Earth and Environmental Science : conference proceedings, 2020)

10 I.M. Bamatov, E.V. Rumyantsev, A.Kh. Zanilov. Influence of biopolymericmodification of mineral fertilizers on the productivity and quality of winter wheat grain, 32023 (IOP Conference Series: Earth and Environmental Science : conference proceedings, 2020)

11. S.N. Kostarev, T.G. Sereda, O.V. Kochetova, K.A. Sidorova, Technological and constructor solutions for the design of silage trenches using CAD, 42010 (IOP Conference Series: Earth and Environmental Science : conference proceedings, 2020)

12. W. Kaim, A. Das, J. Fiedler, S. Záliš, B. Sarkar, Coordination Chemistry Reviews, 404, $213114(2020)$

13. I. Gołaś, A. Gotkowska-Płachta, J.A. Potorski, The Handbook of Environmental Chemistry, 87, 159 (, 2020)

14. M. Nsenga Kumwimba, X. Li, T. Lotti, E. Şenel, F. Suanon, Chemosphere 238, 124627 (2020)

15. L.S. Rybnikova, P.A. Rybnikov. Mine Water and the Environment, 39, 464 (2020) 